\title{
The market for transportation-land use integration: Do developers want smarter growth than regulations allow?
}

\author{
JONATHAN LEVINE* \& ASEEM INAM \\ Taubman College of Architecture and Urban Planning, The University of Michigan, 2000 Bonisteel \\ Blvd., Ann Arbor, MI 48109-2069, USA \\ (*Author for correspondence, E-mail: jnthnlvn@umich.edu)
}

Key words: smart growth, travel behavior, zoning

\begin{abstract}
Transportation and land use research of the past decade has focused in large part on the question of whether manipulating land uses in the direction of "smart growth" alternatives can reduce vehicle miles traveled (VMT) or otherwise improve travel behavior. Yet the notion of "manipulating" land uses implies that the alternative is somehow self-organized or market-based. This view appears to underestimate the extent to which current planning interventions in the United States - largely focused on lowering development densities, mandating ample road and parking designs, and separating land uses - impose an auto-oriented template on most new development. Rather than a market failure, the paucity of "smart growth" alternatives may be a planning failure - the result of municipal regulatory exclusion. This problem definition would shift the burden of proof for policy reform, as uncertainty in travel-behavior benefits would hardly justify the continuation of exclusionary regulations. If municipal regulations in fact constrain alternatives to lowdensity, auto-oriented development, one would expect developers to perceive unsatisfied market interest in such development. This article studies, through a national survey (676 respondents), US developers' perceptions of the market for pedestrian-and transit-oriented development forms. Overall, respondents perceive considerable market interest in alternative development forms, but believe that there is inadequate supply of such alternatives relative to market demand. Developerrespondents attribute this gap between supply and demand principally to local government regulation. When asked how the relaxation of these regulations would affect their product, majorities of developers indicated that such liberalization would lead them to develop in a denser and more mixed-use fashion, particularly in close-in suburban locales. Results are interpreted in favor landpolicy reform based on the expansion of choice in transportation and land use. This view contrasts with a more prevalent approach which conditions policy interventions on scientific evidence of travel-behavior modification.
\end{abstract}

\section{Introduction}

Transportation policy in developed nations faces a number of urgent imperatives, including mitigating air pollution and greenhouse gas production, and coping with congestion in the face of constrained capacity to construct and expand roadways. As an outcome of this urgency, research into the interaction of land use and transportation has largely focused on the capacity of alter- 
native land use approaches - including transit-oriented development, new urbanist neighborhoods, jobs-housing balance, and compact, mixed use growth in general - to moderate growth in vehicle miles traveled (VMT). These development forms are referred to collectively in this study as "alternative" development, in that they constitute alternatives to auto-oriented, low-density suburban patterns.

Considerable debate surrounds the issue of the impact of alternative development on travel behavior; the impossibility of controlled experimentation in this area has led to conflicting interpretations of the scientific data. On the one hand, residents of neighborhoods that are accessible, compact, mixed in terms of their land uses, and amenable to pedestrianism and transit use drive less than their counterparts in more auto-oriented and suburban neighborhoods. But this simple observation is complicated both by demographics that vary between neighborhood types and by neighborhood self-selection; people may select neighborhoods that offer them the opportunity to travel in certain ways, a phenomenon that complicates the establishment of causal relationships. In the face of such methodological complexities, the prospects for resolving unambiguously the impact of land-use policy on VMT remain remote.

Some authors (Giuliano 1999; Boarnet \& Crane 2001) argue that in the absence of reasonable scientific certainty regarding the influence of land use on travel behavior these alternatives have a limited role to play in transportation policy. This view implies that VMT reduction, or other travel behavior impacts are the principal transportation-policy criterion by which these land use alternatives should be judged. That is, a failure in the VMT-reduction test would undermine the rationale for the planning interventions that are presumed to be needed in order for these alternatives to arise. Thus some researchers, notably Boarnet and Crane (2001), have called for concerted efforts to understand the link between land use development and travel behavior better as a prerequisite to the formation of sensible policy based on this connection. Much of this current effort is documented in reviews of current studies by Ewing and Cervero (2001) and Crane (1999).

While improved social-scientific understandings of the influence of built form on travel behavior can enlighten the debate, such scientific advances alone will not resolve the controversy over transportation and land use transportation policy. This is because travel-behavior studies leave unexplored the factors underlying the relative paucity of alternative development to begin with. One guiding notion is that the relative lack of such alternatives in the United States stems from weak market interest on the part of potential renters and buyers. Under this explanation, scientific establishment of the efficacy of these developments in modifying travel behavior and thus mitigating transportation's external costs would be a reasonable criterion for public intervention in this 
realm. And the mode of intervention - should benefits be established with sufficient certainty - would be "market forcing" and might include regulations and subsidies to alter outcomes that the market might not otherwise have produced. Under this formulation, interventions on behalf of alternative development forms are evaluated as a method of coping with the market failures of sprawl.

But as Downs (1999, p. 963) has written: "[T]he belief that sprawl is caused primarily by market failures is based on the false assumption that there is a freely operating land use market in US metropolitan areas. No metropolitan area has anything remotely approaching a free land use market because of local regulations adopted for parochial political, social and fiscal purposes." It may be that the provision of alternative development in the US is constrained through regulatory obstacles such as zoning, transportation standards, or neighbors' exclusionary sentiment that is played out through local government intervention. To the extent that this explanation holds, removal of such regulatory obstacles would be geared at increasing households' effective range of choice of land-use and transportation environments; any scientifically established benefits in travel behavior modification could be seen as a desired benefit but not the sine qua non of regulatory liberalization. The mode of intervention would be altered as well; policy attention would not be based on the logic of market forcing, but would be aimed at removing obstacles to such development, and reserving territory to facilitate its orderly agglomeration. These liberalized policies would produce alternative development only in areas where land development market could support these alternatives. Giuliano (1999, p. 20) suggests that reducing zoning restrictions would increase development densities, though because she sees few congestion or VMT benefits, she does not view this outcome as particularly relevant to transportation policy. By contrast, we argue that increasing household capacity to satisfy transportation and land use preferences is central to transportation policy, independent of payoffs in mitigation of congestion or VMT.

This study argues that land use and transportation regulations constitute a binding constraint on alternative development forms in many areas of the US, limiting households' ability to choose these options. To the extent that this explanation holds, one would expect private land developers to perceive unmet demand for alternative development forms. Evidence is presented here of an original US survey of developers, randomly selected from the database of the Urban Land Institute in Washington, DC, the premiere national organization of land developers. Overall, the survey reveals considerable interest on the part of the private development community in developing in a fashion that is more compact that regulations currently allow. This interest was spread broadly, but was particularly high in the densely settled regions of the mid-Atlantic and the Northeast, and in close-in suburban locales in metropolitan areas nationwide. 


\section{Regulation as constraint on transportation-land use innovation}

In practice, a number of current planning and transportation regulations currently impede the development of these alternatives in the US context. These regulations come in the form of zoning that seeks to lower densities and separate land uses and transportation regulations that specify ample roadways and large parking lots. For example, land use conflicts frequently arise on the basis of developers' desire to build more densely than allowed by local government general plans, zoning ordinances or negotiated agreements (Fischel 1985; Bogart 1998). Gordon and Richardson (2001, p. 140) while arguing against the transportation or environmental relevance of New Urbanist projects, allow that "[a]n interesting question, especially with regard to infill projects, is whether these alternatives are acceptable to the community at large, as opposed to prospective purchasers." The will of the community at large is not automatically relevant to the prospects for developing New Urbanist projects, but is made operational through the municipal exercise of the state's police-power regulation. We argue that policy question ought to hinge on the desirability of those regulations, rather than construing them to some manner of market force.

Willson (1995) studied municipal parking requirements, and concluded that these both spur an oversupply of parking and the development of metropolitan sprawl. Pendall (1999) examined the impact of a range of land use controls on sprawling metropolitan patterns, concluding that development caps and lowdensity-only zoning are significant factors behind the development of sprawling metropolitan forms. Talen and Knaap (2003, p. 357) surveyed municipal land use regulations in Illinois for evidence of "smart growth" policies. These were exceedingly rare, and more common were regulations that "are requiring sprawl development de facto." In many cases it is not the rigidity of the regulations per se that constitutes an obstacle to alternative development, but the willingness of the local decision makers to employ the regulatory function to exclude these alternatives. While mechanisms for altering regulatory obstacles abound (Kavage et al. 2002), the political will to employ them may be in shorter supply.

A demand-based study (Levine et al. 2002) analyzed the fit between stated household preferences and revealed locational choices in metropolitan Boston and Atlanta. Whereas Boston is a region with housing choices distributed across a range of neighborhood types and densities, metropolitan-Atlanta development occurred in more universally auto-oriented fashion. The study modeled sensitivity of households' locational choices to their transportation and landuse preferences, finding these to be considerably more responsive in Boston than in Atlanta. The study concluded that greater variety of transportation and land use environments in Boston supported a closer match between preferences and choices than the more uniform auto-oriented environment of Atlanta. 
If land use and transportation choices have been limited by current regulation, remedying such constraints on choice would be highly relevant to transportation policy, quite independently of any demonstrated effects on VMT. This is because removing unwarranted regulatory obstacles would allow people to forge a closer match between their transportation and land use preferences on the one hand and neighborhood choices on the other. We refer to this argument as a "choice-based" rationale for alternative development forms. Such a rationale rests in part on the notion that the private development market is capable of providing more alternative development than current regulations allow. Such desired growth may take the form of expansion in sheer numbers of housing units developed in a more compact, pedestrian- and transit-friendly fashion; in addition, it may take the form of more accessible locations for such developments. It is considerably more difficult, because of local opposition, to create an alternative development in the heart of an already developed community than in undeveloped territory beyond the metropolitan fringe. This may imply a constraint on the supply of alternative neighborhood styles in particular locations, in addition to restrictions that may limit supply overall.

\section{Developer survey}

If land-use and transportation regulation is in fact a binding constraint on the production of alternative development forms, one would expect developers to express desires for more such development than is allowed under current municipal planning practices. An original national survey was conducted among US developers in order to assess perceptions of the impact of planning regulations on their products. Principal themes of the survey included:

- Perceptions regarding the market for alternative development. Is it sufficient or insufficient currently to expand the provision of alternative development forms? Is the supply of such development adequate currently to satisfy its demand? If not, what are obstacles to its expansion?

- Developers' experience with proposing and developing these alternatives. How are such proposals handled, modified, accepted or rejected by the planning system?

- Strategic behavior in response to planning interventions. In what ways do developers modify their behavior in anticipation of the intervention of the planning function?

- Impact of regulations on the densities and land-use mixing of development. How do developers believe that their products would change if land-use and transportation regulations were liberalized? 
The survey defined alternatives to conventional, low-density, automobileoriented, suburban development in the following ways:

- higher than usual densities;

- a mix of land uses;

- a variety of housing types close together;

- pedestrian- or transit-oriented design;

- availability of a range of transportation modes; and

- easy accessibility to major destinations.

"Alternative development" as referred to in the survey and throughout this report is development that has a significant share of the characteristics described above. In the case of the survey, what counts as "alternative development" was a function of a developer's individual perceptions; undoubtedly, some developers may consider a number of their products to be "alternative" while many architects or urban planners evaluating these same products may judge them to be quite conventional. Data regarding a developer's individual experience with "alternative" development must be assessed in this light. Data regarding developers' desired density of construction and land-use mixing would not be subject to this limitation. Nevertheless, the entire survey was designed to measure developers' perceptions, as evidence - within the context of the growing literature on the topic - of the impact of land-use and transportation regulations on the capacity for the current US planning regime to provide for alternative development forms.

\section{Study methodology}

Two data sources were considered for use as a sampling frame for this study: the membership of the National Association of Home Builders, and the developer membership of the Urban Land Institute. While developer and builder functions are sometimes combined in a single firm, the two roles are readily distinguishable from each other. Builders construct homes and commercial structures on land that is prepared for development, generally including subdivision, permitting, and infrastructure provision. In contrast, developers' role is to bring land to the point where it can be built upon; thus they manage land purchase and assembly, as well as the functions referred to above. By the time the builder is involved, there is frequently little latitude regarding the directions of development, as the fundamental template has already been established. In contrast, developers have significant leeway to propose a number of different development forms. For this reason, the membership of the Urban Land Institute, the nation's leading association of land developers, served as a basis for development of the survey sample. 
Table 1. Response to survey questionnaire.

\begin{tabular}{ll}
\hline Initial questionnaires mailed & 2000 \\
Returned for bad addresses & 47 \\
Returned incomplete with indication that the survey respondent & 19 \\
is not a developer & 706 \\
Returned completed & $36.5 \%$ \\
$\begin{array}{l}\text { Response rate } \\
\text { Qualifying respondents (i.e., residential, commercial or } \\
\text { mixed use developers) }\end{array}$ & 693 \\
\hline
\end{tabular}

The Urban Land Institute staff selected from its membership database all those individuals who were classified as "developers." In all 4,183 individuals matched this description. Questionnaires were mailed in winter 2001 to a simple random sample of 2000 drawn from this group. The cover letter indicated the purpose of the survey, and offered ten prizes of $\$ 100$ each to randomly selected survey respondents. Questionnaires were marked with a code identifying the respondents, and several weeks after the initial mailing, a follow-up postcard was sent to people who had not responded to the initial mailing. Several weeks after the follow-up postcard, a duplicate questionnaire was sent to people who had still not responded. Each of the additional mailings triggered new responses, and overall the response rate to the survey was $36.5 \%$ (Table 1).

To analyze the survey data, multi-state regions were defined, based on the regions of the Department of Housing and Urban Development (HUD). In some cases, two HUD regions were combined in order to ensure reasonable sample sizes within each geographic unit. As a check on sample bias, locations (the only variable comprehensively available) were compared for respondents and the developer population as a whole; the two distributions matched closely (Table 2). Respondents were also asked the geographic areas in which they worked. The regions, together with the surveys received from each are shown in Table 3.

\section{The market for alternative development}

Overall, developers perceive considerable market interest in alternative development. Most of the nationwide sample estimated that at least $10 \%$ of households are interested in such alternatives, and over one third of the sample saw a potential market of at least $25 \%$ (Table 4). The highest levels of interest were perceived by developers in the dense Northeast and Mid-Atlantic regions; considerably less interest was reported by developers in the country's central areas: Midwest, Plains, Mountains and South Central Regions. Nationwide and other multi-region developers reported high levels of interest, comparable to those reported along the East Coast. It is notable, however that even among 
Table 2. Comparison of respondents' location with Urban Land Institute Developer Population.

\begin{tabular}{llc}
\hline Region of office location & $\begin{array}{l}\text { Percent of survey } \\
\text { respondents }\end{array}$ & $\begin{array}{l}\text { Percent in Urban Land } \\
\text { Institute database }\end{array}$ \\
\hline Northeast & $10.3 \%$ & $11.8 \%$ \\
Mid-Atlantic & $10.5 \%$ & $9.5 \%$ \\
Southeast/Carribean & $19.2 \%$ & $18.8 \%$ \\
Midwest & $13.5 \%$ & $13.1 \%$ \\
South Central & $8.0 \%$ & $10.0 \%$ \\
Great Plains, Rocky Mountains & $9.9 \%$ & $7.1 \%$ \\
Pacific and Northwest & $28.6 \%$ & $29.7 \%$ \\
$n$ & 693 & 4183 \\
\hline
\end{tabular}

Table 3. Geographic distribution of responses by area of work.

\begin{tabular}{llc}
\hline Region & States represented & $\begin{array}{c}\text { Number of } \\
\text { valid responses }\end{array}$ \\
\hline Northeast & CT, MA, NJ, NY, VT & 63 \\
Mid-Atlantic & DC, MD, PA, VA, WV & 59 \\
Southeast/Carribean & AL, FL, GA, KY, MS, NC, PR, SC, TN & 134 \\
Midwest & IL, IN, MI, MN, OH, WI & 83 \\
South Central & AR, LA, NM, OK, TX & 56 \\
Great Plains, Rocky & CO, IO, KS, MO, MT, NE, ND, SD, UT, & 55 \\
Mountains & WY & \\
Pacific and Northwest & AZ, CA, HI, ID, NV, OR, WA & 182 \\
Multi-region developers & All & 50 \\
Total & & 682 \\
No region reported & & 11 \\
Grand total & & 693 \\
\hline
\end{tabular}

the regions where comparatively low interest was perceived, around $70 \%$ of developers thought that a market existed for at least $10 \%$ of households. In general, the market for such development is perceived as more than "niche" in character.

Assessments of the size of the potential market need to be interpreted in light of perceptions about the adequacy of current supply of alternative development forms, and respondents were asked to assess the sufficiency of current supply in their regions. While notable differences existed between regions, the assessment overall was of inadequate supply of alternatives currently (Table 5); under $15 \%$ of respondents believed that supplies were currently both ample and in the appropriate locations. The share of developers viewing supplies as adequate and appropriately located varied from a low of $2 \%$ in the Northeast to a high of around $20 \%$ in the mid-Atlantic region. About one-fifth of developers nationwide judged current supplies to be adequate overall, but not necessarily in the right locations. This may be indicative of the greater ease 
Table 4. Developer perception of market interest in alternative development.

\begin{tabular}{|c|c|c|c|c|c|}
\hline \multirow[t]{2}{*}{ Region } & \multicolumn{5}{|c|}{$\begin{array}{l}\text { What share of the households in your markets is interested in } \\
\text { alternative development? }\end{array}$} \\
\hline & None $(\%)$ & $\begin{array}{l}1 \% \text { to } \\
<10 \%\end{array}$ & $\begin{array}{l}10 \% \text { to } \\
<25 \%\end{array}$ & $\begin{array}{l}25 \% \text { to } \\
<50 \%\end{array}$ & $\begin{array}{l}50 \% \text { or } \\
\text { more }\end{array}$ \\
\hline Northeast & & 20.7 & 43.1 & 15.5 & 20.7 \\
\hline Mid-Atlantic & 1.7 & 17.2 & 31.0 & 29.3 & 20.7 \\
\hline \multicolumn{6}{|l|}{ Southeast/ } \\
\hline Carribean & 0.8 & 26.5 & 43.9 & 14.4 & 14.4 \\
\hline Midwest & 1.2 & 21.0 & 38.3 & 30.9 & 8.6 \\
\hline South Central & 3.6 & 25.0 & 50.0 & 16.1 & 5.4 \\
\hline Great Plains, & & 30.8 & 32.7 & 25.0 & 11.5 \\
\hline Rocky Mountains & & & & & \\
\hline Pacific and Northwest & 1.7 & 17.3 & 41.3 & 24.0 & 15.6 \\
\hline Multi-region developers & & 22.0 & 34.0 & 22.0 & 22.0 \\
\hline Total sample & 1.2 & 21.9 & 40.2 & 21.9 & 14.7 \\
\hline
\end{tabular}

of providing alternatives in undeveloped territory beyond the metropolitan fringe than in locales that already enjoy high levels of accessibility.

In conjunction, Tables 4 and 5 establish perceptions of significant demand coupled with inadequate supply of alternatives. The perceived reasons for the apparent undersupply are reported in Table 6. Respondents were asked to indicate all significant obstacles to the expansion to the supply of alternative developments. With the exception of developers in the South Central district, few respondents saw lack of market interest to be an obstacle to the further development of the options, but an overwhelming majority of respondents

Table 5. Perceptions of adequacy of current supply of alternative development.

\begin{tabular}{llllr}
\hline Region & \multicolumn{2}{l}{$\begin{array}{l}\text { Is there adequate supply of alternative development in } \\
\text { existing housing and new construction? }\end{array}$} & $n$ \\
\cline { 2 - 4 } & $\begin{array}{l}\text { Enough and in } \\
\text { right locations } \\
(\%)\end{array}$ & $\begin{array}{l}\text { Enough but not } \\
\text { in right locations } \\
(\%)\end{array}$ & Not enough (\%) & \\
& 1.7 & 12.1 & 86.2 & 58 \\
\hline Northeast & 19.3 & 12.3 & 68.4 & 57 \\
Mid-Atlantic & 18.9 & 25.8 & 55.3 & 132 \\
Southeast/Carribean & 15.2 & 22.8 & 62.0 & 79 \\
Midwest & 18.2 & 30.9 & 50.9 & 55 \\
South Central & 13.5 & 15.4 & 71.2 & 52 \\
Great Plains, Rocky & 13.6 & 14.8 & 71.6 & 176 \\
Mountains & 12.8 & 10.6 & 66.6 & 656 \\
Pacific and Northwest & 14.6 & 18.6 & 66.8 \\
Multi-region developers & & &
\end{tabular}


418

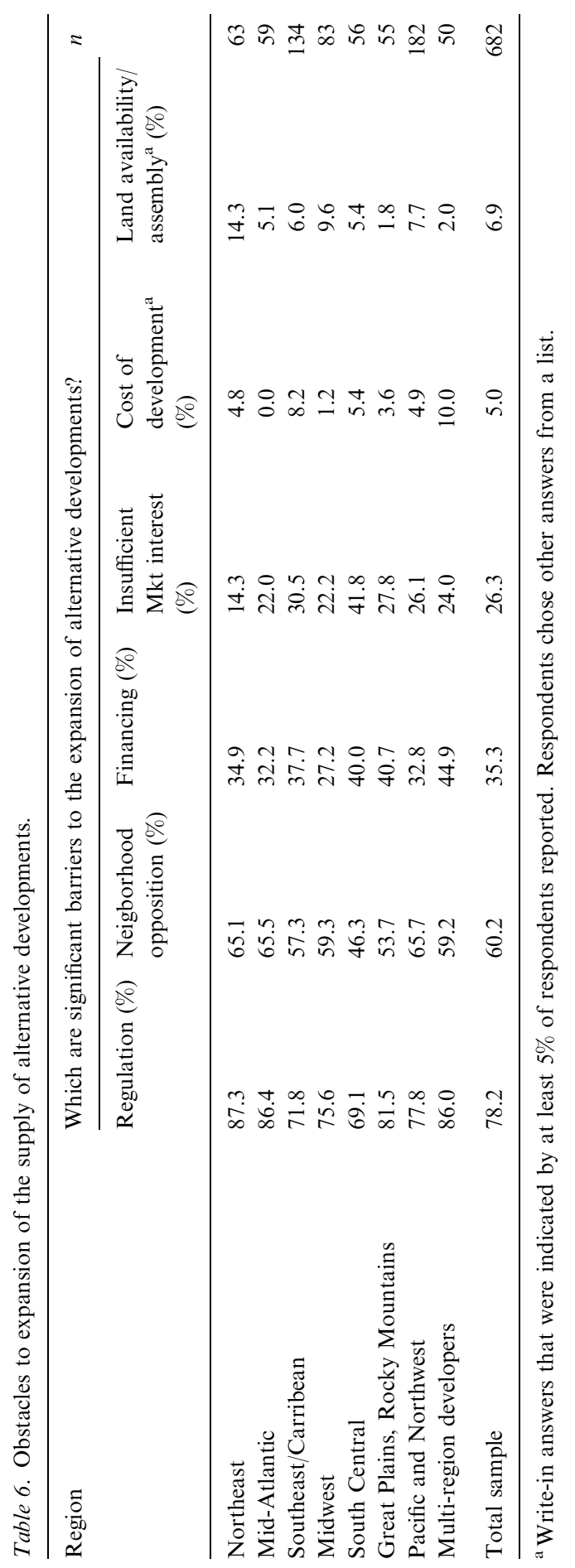


viewed local regulations to be a significant obstacle. The second most broadly recognized obstacle was opposition on the part of neighborhood residents. It should be pointed out that in practice, "neighborhood opposition" and "regulation" as an obstacle to the development of alternatives are identical explanations. Neighbors opposed to development are unable legally to halt such development through direct action; rather their mobilization is channeled through the municipal land use authority, such as the city or the county. The authority in turn can choose to use the regulatory power delegated to it from the state to exclude, modify or permit the development in question.

The other significant difficulty reported is securing financing. Developers often portray lenders as conservative and unwilling to finance alternatives conventional development. In the current survey, roughly one third of respondents voiced this claim.

In order to focus this issue further, respondents were asked to indicate the single most important obstacle to the further expansion of alternative development forms (Table 7). Governmental regulations hostile to such development were by far the most prevalent obstacle identified. "Neighborhood opposition," which is fundamentally the same explanation, was the second most cited obstacle. In all, nearly $60 \%$ of respondents nationwide identified one of these two factors as primary obstacles to the growth in alternative developments. In contrast, only $15 \%$ identified lack of market interest as the primary obstacle to growth.

These results are corroborated by the findings of Table 8 , which reports respondents' perceptions of current market demand for alternative development. Over $60 \%$ of respondents expressed agreement with the statement, "In my region there is currently enough market interest to support significant expansion of these alternative developments." This ranged from a high of nearly $70 \%$ in the Midwest to a low of just over $40 \%$ in the South Central region. While developers in this region perceived less interest than their counterparts elsewhere, it is useful to note that even in this area, the statement elicited more agreement than disagreement overall.

\subsection{Firms' experience with alternative development}

Respondents were asked about their firms' own experiences with proposing alternative development. Over one third of the firms have report no such proposals (Table 9). Of those who have proposed such developments nearly half have had the experience of the proposal being rejected. A larger number have had proposals for alternative development significantly altered by the planning process; over two thirds of firms who have presented such proposals have had at least some share of the proposals significantly altered. "Alteration" 
Table 7. Developers' perception of the "single most important obstacle" to alternative development.

\begin{tabular}{lr}
\hline Lack of market interest & $15.0 \%$ \\
Local regulations & $42.7 \%$ \\
Financing & $9.2 \%$ \\
Neighborhood opposition & $17.4 \%$ \\
Other & $15.6 \%$ \\
\hline
\end{tabular}

Table 8. Developer perception of market interest in alternative developments.

\begin{tabular}{|c|c|c|c|c|c|c|}
\hline \multirow[t]{2}{*}{ Region } & \multicolumn{5}{|c|}{$\begin{array}{l}\text { In my region, there is currently enough market interest } \\
\text { to support significant expansion of these alternative } \\
\text { developments }\end{array}$} & \multirow[t]{2}{*}{$n$} \\
\hline & $\begin{array}{l}\text { Strongly } \\
\text { disagree (\%) }\end{array}$ & $\begin{array}{l}\text { Disagree } \\
(\%)\end{array}$ & $\begin{array}{l}\text { Neutral } \\
(\%)\end{array}$ & Agree (\%) & $\begin{array}{l}\text { Strongly } \\
\text { agree }(\%)\end{array}$ & \\
\hline Northeast & 6.5 & 16.1 & 16.1 & 37.1 & 24.2 & 62 \\
\hline Mid-Atlantic & 5.1 & 18.6 & 11.9 & 49.2 & 15.3 & 59 \\
\hline Southeast/Carribean & 6.0 & 17.3 & 18.0 & 41.4 & 17.3 & 133 \\
\hline Midwest & 6.0 & 14.5 & 10.8 & 51.8 & 16.9 & 83 \\
\hline South Central & 8.9 & 25.0 & 25.0 & 33.9 & 7.1 & 56 \\
\hline $\begin{array}{l}\text { Great Plains, } \\
\text { Rocky Mountains }\end{array}$ & 1.9 & 11.3 & 20.8 & 49.1 & 17.0 & 53 \\
\hline Pacific and Northwest & 5.6 & 13.9 & 15.6 & 37.2 & 27.8 & 180 \\
\hline Multi-region developers & 2.0 & 20.0 & 14.0 & 44.0 & 20.0 & 50 \\
\hline All respondents & 5.5 & 16.4 & 16.3 & 42.0 & 19.8 & 676 \\
\hline
\end{tabular}

Table 9. Firms' experience with proposing alternative developments.

\begin{tabular}{lll}
\hline & $\begin{array}{l}\text { What share of your firm's } \\
\text { proposals for alternative } \\
\text { development has been } \\
\text { rejected by local governments? }\end{array}$ & $\begin{array}{l}\text { What share of your firm's } \\
\text { proposals has been signifi- } \\
\text { cantly altered by the plan- } \\
\text { ning and approval process? }\end{array}$ \\
\hline No proposals made & $35.3 \%$ & $35.9 \%$ \\
None & $35.9 \%$ & $19.9 \%$ \\
$1 \%$ to $<10 \%$ & $9.8 \%$ & $8.3 \%$ \\
$10 \%$ to $<25 \%$ & $6.8 \%$ & $8.7 \%$ \\
$25 \%$ to $<50 \%$ & $5.4 \%$ & $9.9 \%$ \\
$50 \%$ or more & $6.8 \%$ & $17.3 \%$ \\
$n$ & 663 & 654 \\
\hline
\end{tabular}

for the purposes of the survey was defined as reduction in the density, mixed use character, housing variety or pedestrian or transit orientation of the development. 
Of the respondents that reported that at least some of their alternative proposals had been significantly modified in the course of the planning process, over $80 \%$ indicated reductions in density as a modification that had occurred. This was considerably greater than any of the other modifications, including imposed change in the mixed use character, change in the variety of housing types, or change in the share of mixed use or attached housing. Fewer than $20 \%$ of those with experience in having proposals modified reported reduction in the pedestrian or transit orientation of the development.

Table 10 may assist in interpreting the entire study regarding the definition of "alternative." Even among those who have not made any such proposals, higher than usual densities may be the defining characteristic of "alternative" development. Clearly it is the attribute that has generated the most friction with the planning process. Transportation and land-use researchers will be quick to point out that designs for walkablity are based not merely on density, but rather incorporate design elements of public space, mixed land uses, pedestrian-friendly design, and others. It may be that many of the proposals referred to in Table 10 would not, in fact count as "alternative" by many of these design theorists. Yet for generating accessibility of metropolitan form, and for increasing housing supply in accessible areas, density may in fact be the key. Thus the proposal for a plain apartment building or condominium complex that will never win any design awards may serve to enhance metropolitan accessibility, if it increases housing supplies in areas of the region that are close to major work and non-work destinations.

\subsection{Developers'strategic behavior}

One potential outcome of the interactions between developers and the planning process is strategic behavior on the part of developers that anticipates the actions that they expect from planning authorities. For example, developers may refrain from proposing alternative development if they expect that the

Table 10. Modifications to proposed alternative developments by the planning and approval process.

\begin{tabular}{lc}
\hline Modification as an outcome of the planning process & \\
\hline Density reduced & $81.7 \%$ \\
Mixed use character reduced & $47.2 \%$ \\
Change in variety of housing types & $29.4 \%$ \\
Change in share of mixed use or attached & $33.2 \%$ \\
Change in pedestrian or transit orientation & $19.1 \%$ \\
$n$ & 235 \\
\hline
\end{tabular}


proposals would be rejected. Preparing proposals for development is costly, and developers would only want to bear these costs if there is a reasonable probability of the investment bearing fruit. Similarly, developers may anticipate planning intervention and may proactively lower proposed development densities to attempt to expedite project approval. Conversely, developers may propose higher than desired densities in order to have something to give away in the bargaining that is often part of the planning process.

Table 11 considers these various possibilities. In all three cases, more respondents believe that the strategic behavior takes place than disagree. The single most commonly reported strategy is the increasing of proposed densities; nearly $50 \%$ of respondents agree that their firm proposes higher than desired densities in order to have bargaining chips to give away. This finding is relevant to the current study in two ways. First, it provides a note of caution. Not every instance in which the planning process lowers proposed development densities is in fact constraining the land-development market. By the same token, the prevalence of the other two strategies suggest that there is some degree of selfcensorship going on the part of the developers; the universe of proposed alternative developments does not represent all potential developments. Clearly any interpretation of empirical studies of development proposals would be hampered by these phenomena. Moreover, the prevalence of the strategy of proposing higher-than-desired densities provides evidence that in the developer's mind at least, the expected outcome of many planning processes is a reduction in development densities. This contradicts the view that promotion of density is the product of planning intervention into the development market (and one that thus demands provable benefits in VMT reductions to be supportable).

\subsection{Impact of the planning function on development}

The view that alternative development amounts to a directed reshaping of people's transportation behavior implies that the land-development market seeks to develop in a low-density, automobile-oriented fashion. Under this view, planning interventions seek to "encourage" the land development market into more compact, mixed-use, or walkable forms. To examine this notion, survey respondents were asked to indicate the impact that relaxation of planning and transportation regulations would have on the density and the mixed-use character of their products. In particular, respondents were asked to indicate whether relaxation of density, floor area ratio, setback or lot-size regulations would lead them to build more or less densely, and in a more or less mixed-use fashion. Respondents were also able to indicate "no change" as an outcome of relaxation of regulations. 


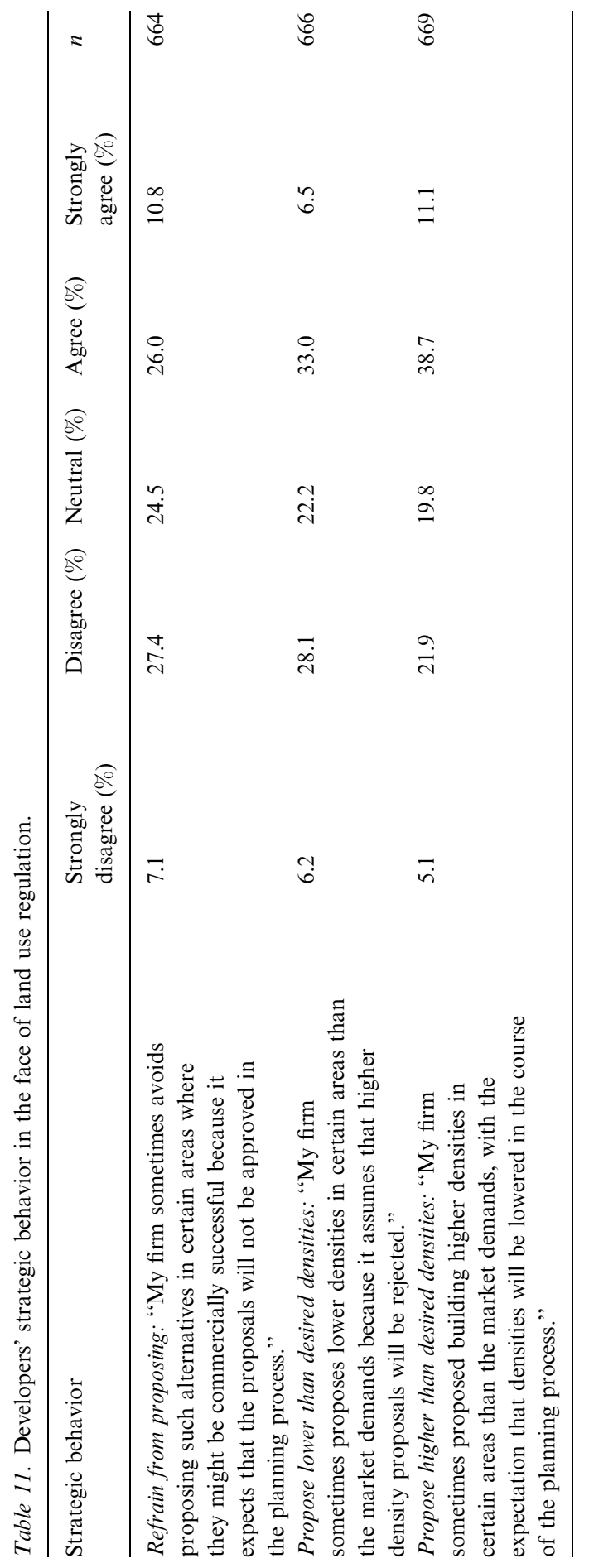




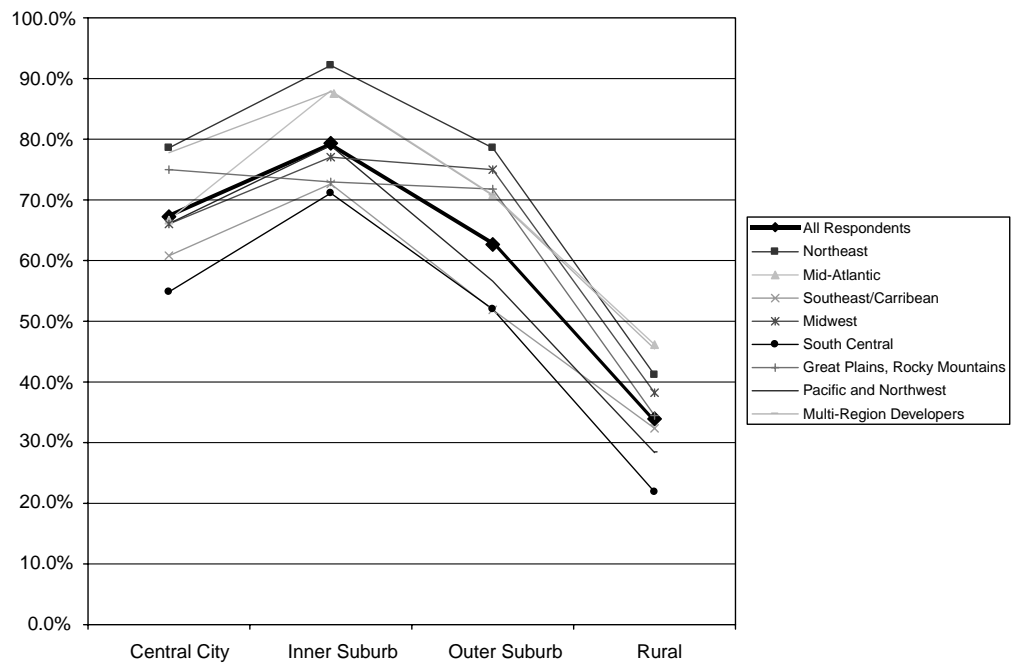

Figure 1. Share of respondents indicating that easing of land use regulations would lead to denser development, by metropolitan setting.

Results are presented in Figure 1 for density and Figure 2 for mixed use. For development in central cities, inner suburbs and outer suburbs, majorities of developers indicated that relaxation of regulations such as zoning, floor area ratio or transportation standards would lead them to build more densely; the figures for rural areas were considerably less. The greatest interest in

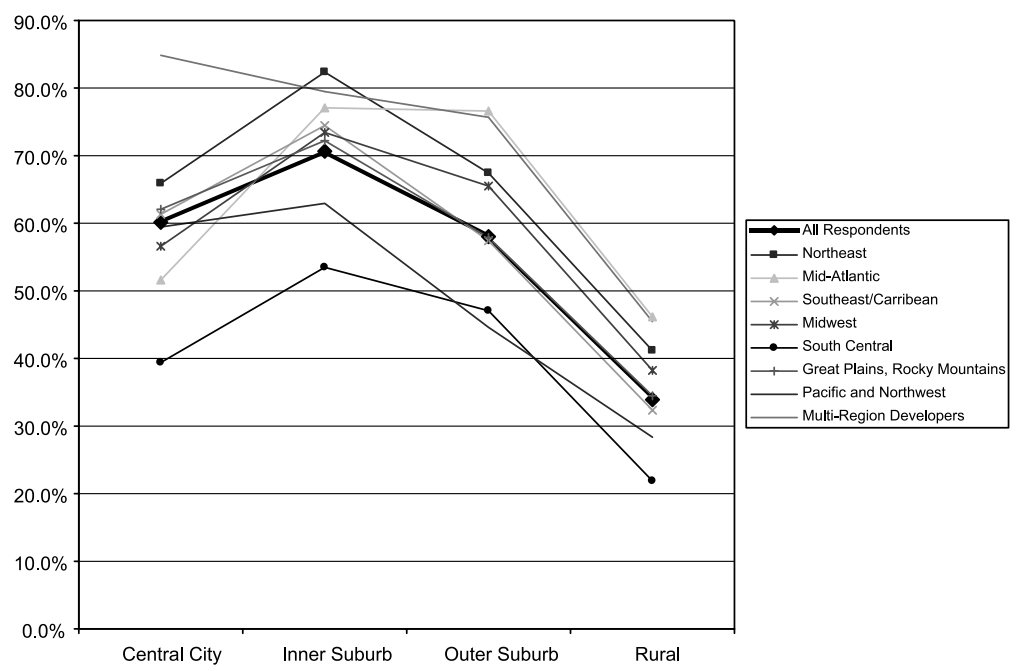

Figure 2. Share of respondents indicating that easing of land use regulations would lead to more mixed use development, by metropolitan setting. 
development in a denser or more mixed-use fashion than regulations allowed was found in the inner suburbs. In cities, denser development is generally allowed by regulation, and in rural areas there tends to be little pressure for dense development to begin with. Thus it is in the close-in suburbs, rather than those on the metropolitan fringe, where there is the greatest reported gap between the desired density and mixed-use characteristics of development on the one hand and that which is permitted by regulation on the other.

This suggests a process in which low-density development occurs beyond the metropolitan fringe, with little pressure for more intense development. As the region expands, the "fringe" of an earlier era can become the relatively close-in suburbs of a later period. At that time, pressure for high-density development mounts; yet local sentiment among residents against such development tends to lock an earlier lower-density pattern, and limit market-driven increases in development densities locally.

It is noteworthy that this pattern - a close-in suburban peak in interest in building in a denser or more mixed use fashion than regulations allow - is repeated in virtually every region of the survey. In addition, results of this analysis are consistent with other findings regarding areas of greatest interest in alternative development; developers in the Northeast and Mid-Atlantic expressed very high interest in developing more densely than regulations allow; this figure exceeded $90 \%$ for development of inner suburban areas in the Northeast. Developers in the South Central region exhibited considerably less interest in providing greater density or mixed use than permitted by regulation; nonetheless, this figure exceed $50 \%$ of developers in reference to inner suburban areas.

\section{Conclusion}

Under one widely held view, policy reform on behalf of alternative development is justified, if at all, by the capacity of these land-use forms to affect travel behavior. Interestingly, this view is shared both by many advocates of such development and those who are skeptical of the transportation claims of these proponents. According to this view, the transportation rationale of these developments rests on their claimed capacity to reduce vehicle miles traveled or congestion; absent conclusive scientific proof in this regard, their transportation rationale would be undermined, and the planning interventions that are presumed to be required to bring these alternative development forms about would be unjustified.

Under this view, if alternative development forms reduce driving, policy action on their behalf may constitute a remedy for the market failures of sprawl. By contrast, this study has argued that the lack of alternative development forms is less a market failure than a planning failure, as municipal 
regulations tend to constrain the ability of developers to provide alternatives to low-density, auto-oriented development. This alternative problem definition implies a shifting of the burden of proof as uncertainty in travel-behavior impacts would hardly justify perpetuation of regulations excluding alternative development forms.

Findings reported in this study support this view. On the whole, the random sample of developers studied perceives considerable market interest in alternative development; believes that there is inadequate supply of such alternatives; views local government regulation as the primary obstacle to the further development of these alternatives; and indicates interest in developing more densely and mixed-use than regulations allow, notably in inner suburban areas. Thus it appears that in the perceptions of developers at least, it is hardly more planning intervention that would bring about greater alternative development forms in the US context, but relaxation of restrictive land-use and transportation policies that are excluding these forms to begin with.

Whether alternative development is relevant to transportation policy depends centrally on the question asked. Such development may, over the long period, contribute to moderation in the growth of vehicle miles traveled; this study was not designed to shed any light on that question. But findings here suggest another transportation benefit entirely. To the extent that market interest in alternative development is strong, and that supplies of alternatives are inadequate currently, it suggests that some share of households desires to select land-use and transportation environments that are different from the range currently offered. If the current planning regime has restricted the supply of these options - particularly in inner suburban areas of intense employment development - it has reduced households' choice of their land-use and transportation environments. Expansion of such constrained choice should be a transportation policy concern no less worthy than reduction in VMT.

\section{Acknowledgements}

The support of the Mineta Transportation Institute for this research is gratefully acknowledged. Thanks also to the Urban Land Institute for providing access to its database of developer members for this research.

\section{References}

Boarnet MG \& Crane R (2001) Travel by Design: The Influence of Urban Form on Travel. New York: Oxford University Press.

Bogart WT (1998) The Economics of Cities and Suburbs. Upper Saddle River, NJ: Prentice Hall. 
Crane R (1999) The influence of urban form on travel: An interpretive review. Journal of Planning Literature 15: 3-23.

Downs A (1999) Some realities about sprawl and urban decline. Housing Policy Debate 10(4): $955-$ 974.

Ewing R \& Cervero R (2001) Travel and the built environment - synthesis. In: Redefining, Reevaluating and Reinventing Transit: The Transportation/Land Use/Environmental Connection. Annual Policy and Research Symposium Series. Convened by the UCLA Extension Public Policy Program, UCLA Conference Center, Lake Arrowhead, CA, October 14-16, 2001.

Fischel W (1985) The Economics of Zoning Laws: A Property Rights Approach to American Land Use Controls. Baltimore: Johns Hopkins University Press.

Giuliano G (1999) Land use policy and transportation: Why we won't get there from here. In: Policies for Fostering Sustainable Transportation Technologies. Asilomar Conference Center, Monterey California, 1997. http://www.usc.edu/schools/sppd/lusk/working_papers/2000_1002.pdf.

Gordon P \& Richardson H (2001) The sprawl debate: Let markets plan. Publius: The Journal of Federalism 31(3): 131-149.

Kavage S, Vernez-Moudon A, Cail M, Lee C \& Pergakes N (2002) Implementing TransportationEfficient Development: A Local Overview. Seattle, WA: Washington State Transportation Center, University of Washington.

Levine J, Inam A, Werbel R \& Torng G (2002) Land Use and Transportation Alternatives: Constraint or Expansion of Household Choice? San Jose, CA: Mineta Transportation Institute. MTI Report 01-19. http://transweb.sjsu.edu/pubs.htm.

Pendall R (1999) Do land use controls cause sprawl? Environment and Planning B: Planning and Design 26: 555-571.

Talen E \& Knaap G (2003) Legalizing smart growth: An empirical study of land use regulation in Illinois. Journal of Planning Education and Research 22: 345-359.

Willson RW (1995) Suburban parking requirements: A tacit policy for automobile use and sprawl. Journal of the American Planning Association 61: 29-42. 